\title{
A 12-Year Comparative Analysis of Hodgkin and Non-Hodgkin Lymphomas in Lebanon: Trend Characteristics and 10-Year Projections
}

\author{
Ali H. Abdel Sater ${ }^{1}$, Mohammad Jalloul ${ }^{2}$, Marwan Zein ${ }^{2}$, Zeina Lakis ${ }^{3}$, Hussein H. Khachfe ${ }^{4}$ \\ 1. Medicine, Baabda Governmental Hospital, Beirut, LBN 2. Medicine, Faculty of Medical Sciences, Lebanese \\ University, Beirut, LBN 3. Medicine, Faculty of Medical Sciences, Lebanese University, Beirut, LBN 4. General Surgery, \\ American University of Beirut Medical Center, Beirut, LBN
}

Corresponding author: Hussein H. Khachfe, hhk15@mail.aub.edu

\section{Abstract}

\section{Background}

Hodgkin lymphoma (HL) and non-Hodgkin lymphoma (NHL) are two common malignancies worldwide and in Lebanon. Analysis of their trends plays a crucial role to better understand their origins and risk factors. This study will probe incidences of both types of lymphomas from 2005 to 2016, aiming to compare between the two malignancies according to age and sex and plot projections until 2026.

\section{Methods}

HL and NHL cases from 2005 to 2016 were collected from the National Cancer Registry of Lebanon. Data was stratified according to age and sex. Age-specific and age-standardized incidence rates were analysed using joinpoint regression; 10-year projections were predicted based on logarithmic models.

\section{Results}

Between 2005 and 2016, NHL was significantly more common than HL. NHL was higher in both genders. HL showed a bimodal age distribution while NHL peaked in elderly patients. NHL incidence rates in males increased significantly from 2005 to 2014 while HL incidence rates showed an insignificant rise. Over the next 10 years, NHL and HL cases are expected to increase in Lebanon.

\section{Conclusion}

$\mathrm{HL}$ and NHL are on the rise in Lebanon. Extensive research into the main factors contributing to these lymphomas is crucial in the fight against them. More efforts must be done by the government and health organizations to better control the disease.

Received 05/11/2020

Review began 05/19/2020 Review ended 06/01/2020 Published 06/02/2020

\section{() Copyright 2020}

Abdel Sater et al. This is an open access article distributed under the terms of the Creative Commons Attribution License CC-BY 4.0., which permits unrestricted use, distribution, and reproduction in any medium, provided the original author and source are credited.
Categories: Miscellaneous, Oncology, Hematology

Keywords: hodgkin lymphoma, cancer, lebanon, non-hodgkin's lymphoma

\section{Introduction}

Cancer constitutes the second most common cause of death globally, coming second only to cardiovascular related diseases [1]. In 2018, lymphoid neoplasms were responsible for $3.2 \%$ of all new cancers worldwide [2]. Lymphomas are a group of malignant tumors that originate from aberrant proliferation of lymphoid cells and their precursors [3]. They are broadly classified by the World Health Organization (WHO) into several groups based on cell of origin of the tumor, morphology, immunophenotype, and genetic findings [4]. Lymphoid tumors do not only include Hodgkin lymphomas (HLs) and non-Hodgkin lymphomas (NHLs), but also plasma cell neoplasms and lymphoid leukemias [5].

Risk factors associated with lymphomas include age, gender, ethnicity, and geographic location [6]. Other risk factors include chemicals and radiation exposure, immune system deficiency, HIV infection and family history [7].

Lebanon is a developing country in the Middle East and North African (MENA) region with a population of around six million people as of 2018 [8]. The Ministry of Public Health (MoPH) of Lebanon has established a database that collects new cases of cancers from hospital registries, physician reports, and public and private laboratories. It is known as the National Cancer Registry (NCR) of Lebanon [9].

Using data from 2005 to 2016 collected by the NCR, this study aims to explore the epidemiological characteristics of both HLs and NHLs and compare them among different age groups and genders. The study will also discuss the possible risk factors of $\mathrm{HL}$ and NHL in Lebanon, and plot projections of incidence rates 


\section{Materials And Methods}

Data and records concerning the different types of lymphomas were extracted from the Lebanese NCR database provided by the Lebanese $\mathrm{MoPH}$ [9]. This was done using the International Classification of Diseases, 10th Revision (ICD-10) for HL (C81) and NHL (C82-C85 and C96).

The NCR was screened for the time period 2005-2016, from which age-specific and age-standardized incidence rates, expressed per 100,000 population, were computed. The age-specific incidence rate represented the number of new cancer cases that occurred during a specific time period in a population of a specific age and sex group divided by the number of midyear population of that age and sex group. The agestandardized rates to the world population, henceforth $\mathrm{ASR}(\mathrm{w}) \mathrm{s}$, were the incidence rates that would have been observed in our studied population if they have had the same age composition as a reference population.

The calculated age-specific rates (ASRs) and ASR(w)s were analysed using joinpoint regression analysis with a significance level of 0.05 . The joinpoint model provides detailed information of the trends of the studied hematological malignancies, including the annual percent change (APC) of each type of the selected cancers, over the specified time period.

Using two-tailed t-tests, we also compared the means between different groups of age and genders to search for any significant difference in the incidence rates, considering a P-value $<0.05$ as significant.

By exploiting the extracted and analysed data listed above and using a logarithmic model, we estimated the predictions of HL and NHL incidence rates in Lebanon until 2026. We found the logarithmic model to be the most biologically credible model to follow the trends of cancer over time [10]. The criteria for characterizing the observed trends followed the National Cancer Institute (NCI) guidelines stating that if the APC $>0.5 \%$ the trend is said to be rising; if the APC $<-0.5 \%$, the trend is judged to be declining; and if the $-0.5 \% \leqslant \mathrm{APC} \leqslant$ $0.5 \%$, the trend is judged to be stable [11].

Regarding the need for an Institutional Review Board (IRB) approval, our study is a descriptive epidemiological study with openly accessible, deidentified data available online and published by the Lebanese MoPH. Therefore, no IRB approval was required.

\section{Results}

Over the studied period from 2005 to 2016, a total of 126,480 new cancer cases were reported by the NCR. NHL was found to be the seventh most common cancer in Lebanon contributing to $5.5 \%$ of the total malignancies registered, while HL constituted $1.7 \%$ of new cancer cases during the specified time. An average of 578 NHL cases and 176 HL cases were indexed every year.

Males were significantly more affected by HL (P-value $=0.01,95 \% \mathrm{CI})$ and NHL (P-value < 0.01, 95\% CI). NHL was significantly more prevalent than HL in both genders (P-value $<0.01,95 \% \mathrm{CI})$. HL ASR(w)s of males averaged 4.2 cases per 100,000 and that of females centered at 3.3 cases per 100,000, as shown in Tables 1,2, while NHL ASR(w)s observed had a mean of 14.8 and 12.0 in males and females, respectively (Tables 3, 4). In males, incidence rates recorded peaks of 5.5 HL cases per 100,000 in 2016 and 16.9 NHL cases per 100,000 in 2014, whereas in females, rates mounted to their highest values in 2014 with 3.9 HL cases per 100,000 and 14.3 NHL cases per 100,000 . 


\section{Cureus}

\begin{tabular}{|c|c|c|c|c|c|c|c|c|c|c|c|c|c|c|c|c|c|}
\hline \multirow{2}{*}{ Year } & \multirow{2}{*}{$\begin{array}{l}\text { Average } \\
\text { ASR }\end{array}$} & \multicolumn{16}{|c|}{ ASR } \\
\hline & & $\begin{array}{l}0- \\
4 y\end{array}$ & $\begin{array}{l}5- \\
9 y\end{array}$ & $10-14 y$ & $15-19 y$ & $\begin{array}{l}20- \\
24 y\end{array}$ & $25-29 y$ & $30-34 y$ & $\begin{array}{l}35- \\
39 y\end{array}$ & $40-44 y$ & $45-49 y$ & $50-54 y$ & $55-59 y$ & $\begin{array}{l}60- \\
64 y\end{array}$ & $\begin{array}{l}65- \\
69 y\end{array}$ & $\begin{array}{l}70- \\
74 y\end{array}$ & $75+y$ \\
\hline 2005 & 3.5 & 0.6 & 0 & 3.3 & 5.4 & 5.8 & 3.9 & 3.5 & 5.6 & 3.3 & 2 & 3.4 & 4.3 & 3.1 & 5 & 8.3 & 8.3 \\
\hline 2006 & 3.9 & 0 & 0.5 & 3.2 & 6.7 & 4.3 & 5.8 & 2.7 & 4 & 4.1 & 5 & 8.9 & 5.6 & 0 & 1.6 & 10.2 & 8.2 \\
\hline 2007 & 4.3 & 0 & 1.2 & 3.1 & 4.8 & 4.4 & 4.5 & 9.9 & 3.3 & 8.3 & 4 & 4.6 & 7 & 7.4 & 7.9 & 1.8 & 1.4 \\
\hline 2008 & 4.1 & 0 & 1.4 & 1.8 & 6.2 & 4 & 2.4 & 1.9 & 4.9 & 6.8 & 10.7 & 7.6 & 5.5 & 2.9 & 8.9 & 10.2 & 0 \\
\hline 2009 & 3.9 & 0.6 & 1.9 & 1.8 & 0.9 & 5.4 & 8.8 & 1.9 & 4.8 & 2.9 & 3.5 & 3.8 & 9.5 & 7.2 & 6.5 & 0 & 14.9 \\
\hline 2010 & 5.1 & 0 & 3.2 & 1.3 & 8.8 & 5.4 & 9.8 & 5.6 & 4.7 & 3.8 & 4.6 & 11.1 & 5.3 & 2.8 & 6.4 & 7.4 & 16.5 \\
\hline 2011 & 3.2 & 0.5 & 1.3 & 3 & 1.4 & 3.8 & 2.8 & 4.3 & 1.5 & 3.7 & 7.9 & 2.4 & 6.6 & 5.6 & 10.5 & 2.4 & 3.6 \\
\hline 2012 & 4.8 & 0 & 0.9 & 1.7 & 5.8 & 9.4 & 5.6 & 3.6 & 6.1 & 9.1 & 12.2 & 5.9 & 3.9 & 6.9 & 2.1 & 0 & 5.3 \\
\hline 2013 & 3.6 & 0.4 & 1.5 & 1.5 & 3.9 & 3.9 & 4.9 & 4.7 & 4.6 & 5.6 & 5 & 3.3 & 6 & 2.6 & 7.8 & 6.8 & 1.7 \\
\hline 2014 & 5.1 & 0.3 & 0.6 & 1 & 2.5 & 4 & 2.2 & 7.4 & 3.5 & 5.9 & 12.7 & 5.1 & 14.6 & 7.4 & 20.6 & 12.9 & 19.3 \\
\hline 2015 & 3.8 & 0 & 1.2 & 0.9 & 6.1 & 7.4 & 7.1 & 3.5 & 3.4 & 2.8 & 7 & 5.9 & 4.4 & 3.6 & 0 & 8.5 & 4.7 \\
\hline 2016 & 5.5 & 0 & 2.4 & 1.2 & 4.6 & 5.2 & 7.4 & 5.2 & 6.4 & 9.4 & 5.4 & 12 & 14.5 & 3.7 & 9.3 & 8.5 & 15.9 \\
\hline APC & 1.9 & - & - & $-10.2^{*}$ & -2 & 1.5 & 1.7 & 3.9 & -0.1 & 2.9 & 8.2 & 2.3 & 5.1 & - & - & - & - \\
\hline $\begin{array}{l}\text { P- } \\
\text { value }\end{array}$ & 0.2 & - & - & $<0.05$ & 0.7 & 0.6 & 0.7 & 0.4 & 1 & 0.5 & 0.1 & 0.6 & 0.2 & - & - & - & - \\
\hline $\mathrm{Cl}$ & {$[-1.1,5.1]$} & - & - & $\begin{array}{l}{[-14.6,-} \\
5.5]\end{array}$ & $\begin{array}{l}{[-14.1,} \\
11.9]\end{array}$ & $\begin{array}{l}{[-3.8,} \\
7.1]\end{array}$ & $\begin{array}{l}{[-7.6,} \\
12.0]\end{array}$ & $\begin{array}{l}{[-5.4,} \\
14.0]\end{array}$ & $\begin{array}{l}{[-7.4} \\
7.8]\end{array}$ & $\begin{array}{l}{[-5.4,} \\
11.9]\end{array}$ & $\begin{array}{l}{[-1.3} \\
18.6]\end{array}$ & $\begin{array}{l}{[-7.2,} \\
12.8]\end{array}$ & $\begin{array}{l}{[-2.8,} \\
13.7]\end{array}$ & & 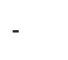 & - & - \\
\hline
\end{tabular}

TABLE 1: Trend analysis for Hodgkin lymphoma ASR per 100,000 in males by age group per year in Lebanon from 2005 to 2016

ASR, age-specific rate; APC, annual percent change

${ }^{*} \mathrm{APC}$ significantly different than zero. 


\section{Cureus}

\begin{tabular}{|c|c|c|c|c|c|c|c|c|c|c|c|c|c|c|c|c|c|}
\hline \multirow[b]{2}{*}{ Year } & \multirow{2}{*}{$\begin{array}{l}\text { Average } \\
\text { ASR }\end{array}$} & \multicolumn{16}{|c|}{ ASR } \\
\hline & & $\begin{array}{l}0- \\
4 y\end{array}$ & $\begin{array}{l}5- \\
9 y\end{array}$ & $10-14 y$ & $15-19 y$ & $20-24 y$ & $25-29 y$ & $30-34 y$ & $\begin{array}{l}35- \\
39 y\end{array}$ & $40-44 y$ & $45-49 y$ & $\begin{array}{l}50- \\
54 y\end{array}$ & $\begin{array}{l}55- \\
59 y\end{array}$ & $\begin{array}{l}60- \\
64 y\end{array}$ & $65-69 y$ & $\begin{array}{l}70- \\
74 y\end{array}$ & $75+y$ \\
\hline 2005 & 3 & 0 & 0 & 3.5 & 4.1 & 6.2 & 2.4 & 3.4 & 2.7 & 2 & 1.8 & 5.7 & 2.6 & 1.4 & 3.3 & 6.8 & 14.5 \\
\hline 2006 & 2.5 & 0 & 0 & 1 & 2 & 5.1 & 6.6 & 3.3 & 0 & 1.3 & 3.6 & 3.3 & 1.3 & 5.4 & 6.5 & 2.2 & 4.1 \\
\hline 2007 & 3.8 & 0 & 0 & 3.3 & 3.9 & 4.3 & 5.4 & 8.6 & 4.1 & 5 & 0.8 & 2 & 11.3 & 5.1 & 3 & 10.9 & 6 \\
\hline 2008 & 2.9 & 0 & 0 & 2.4 & 5.6 & 4.7 & 4.4 & 3.4 & 2.1 & 1.8 & 6.7 & 5 & 2.6 & 2.9 & 2 & 4.9 & 0 \\
\hline 2009 & 3.2 & 0 & 0.5 & 2.8 & 5 & 5.6 & 5.9 & 6.1 & 3.5 & 2.6 & 1.1 & 3.7 & 5.1 & 2.8 & 3.9 & 2.4 & 2 \\
\hline 2010 & 3.6 & 0 & 0 & 1.9 & 3.9 & 7 & 5.3 & 6.6 & 1.4 & 3.4 & 9.7 & 4.8 & 1.3 & 8.3 & 1.9 & 2.4 & 5.8 \\
\hline 2011 & 3.6 & 1.7 & 0.5 & 0.5 & 5.3 & 8.4 & 4.7 & 3.2 & 4.1 & 4.2 & 2.1 & 4.7 & 0 & 6.8 & 3.8 & 9.3 & 7.7 \\
\hline 2012 & 2.7 & 0 & 1.9 & 1.8 & 3.8 & 4.4 & 3.1 & 2.1 & 4 & 3.3 & 2.1 & 0 & 2.4 & 8.1 & 3.7 & 0 & 5.7 \\
\hline 2013 & 3.4 & 0.4 & 0 & 1.2 & 5 & 6.8 & 4 & 5.1 & 4.8 & 4.4 & 2.8 & 4.2 & 3.4 & 0 & 7.1 & 4.3 & 7.1 \\
\hline 2014 & 3.9 & 0.4 & 0.3 & 1.7 & 5.9 & 3 & 5 & 6.2 & 1.1 & 4.7 & 3.4 & 3.9 & 7.3 & 4.7 & 11.7 & 10.2 & 15.2 \\
\hline 2015 & 3.3 & 0 & 1.5 & 2.3 & 3.9 & 7.6 & 8.2 & 6 & 2.6 & 2 & 2.5 & 1.9 & 6.1 & 2.3 & 1.6 & 0 & 3.3 \\
\hline 2016 & 3.5 & 0 & 0 & 1.3 & 4.4 & 5.3 & 6.7 & 5.7 & 2.6 & 3.3 & 3.4 & 2.9 & 6.2 & 9.4 & 3.3 & 4 & 6.7 \\
\hline APC & 1.6 & - & - & -4.8 & 3.1 & 0.2 & 3.6 & 2.4 & - & 5.1 & 3.5 & - & - & - & 1.3 & - & - \\
\hline $\begin{array}{l}\text { P- } \\
\text { value }\end{array}$ & 0.2 & - & - & 0.3 & 0.2 & 0.9 & 0.2 & 0.5 & - & 0.2 & 0.6 & - & - & - & 0.8 & - & - \\
\hline $\mathrm{Cl}$ & {$[-0.8,4.2]$} & & - & $\begin{array}{l}\text { [-14.1, } \\
5.5]\end{array}$ & $\begin{array}{l}{[-2.1,} \\
8.5]\end{array}$ & $\begin{array}{l}{[-5.3,} \\
6.0]\end{array}$ & $\begin{array}{l}{[-2.6,} \\
10.2]\end{array}$ & $\begin{array}{l}{[-5.3,} \\
10.8]\end{array}$ & & $\begin{array}{l}{[-2.6,} \\
13.5]\end{array}$ & $\begin{array}{l}{[-9.3} \\
18.2]\end{array}$ & & & - & $\begin{array}{l}{[-9.4,} \\
13.4]\end{array}$ & & - \\
\hline
\end{tabular}

TABLE 2: Trend analysis for Hodgkin lymphoma ASR per 100,000 in females by age group per year in Lebanon from 2005 to 2016

ASR, age-specific rate; APC, annual percent change 


\section{Cureus}

\begin{tabular}{|c|c|c|c|c|c|c|c|c|c|c|c|c|c|c|c|c|c|}
\hline \multirow[b]{2}{*}{ Year } & \multirow{2}{*}{$\begin{array}{l}\text { Average } \\
\text { ASR }\end{array}$} & \multicolumn{16}{|c|}{ ASR } \\
\hline & & $\begin{array}{l}0- \\
4 y\end{array}$ & $\begin{array}{l}5- \\
9 y\end{array}$ & $10-14 y$ & $15-19 y$ & $20-24 y$ & $25-29 y$ & $30-34 y$ & $\begin{array}{l}35- \\
39 y\end{array}$ & $40-44 y$ & $45-49 y$ & $\begin{array}{l}50- \\
54 y\end{array}$ & $\begin{array}{l}55- \\
59 y\end{array}$ & $\begin{array}{l}60- \\
64 y\end{array}$ & $65-69 y$ & $\begin{array}{l}70- \\
74 y\end{array}$ & $75+y$ \\
\hline 2005 & 3 & 0 & 0 & 3.5 & 4.1 & 6.2 & 2.4 & 3.4 & 2.7 & 2 & 1.8 & 5.7 & 2.6 & 1.4 & 3.3 & 6.8 & 14.5 \\
\hline 2006 & 2.5 & 0 & 0 & 1 & 2 & 5.1 & 6.6 & 3.3 & 0 & 1.3 & 3.6 & 3.3 & 1.3 & 5.4 & 6.5 & 2.2 & 4.1 \\
\hline 2007 & 3.8 & 0 & 0 & 3.3 & 3.9 & 4.3 & 5.4 & 8.6 & 4.1 & 5 & 0.8 & 2 & 11.3 & 5.1 & 3 & 10.9 & 6 \\
\hline 2008 & 2.9 & 0 & 0 & 2.4 & 5.6 & 4.7 & 4.4 & 3.4 & 2.1 & 1.8 & 6.7 & 5 & 2.6 & 2.9 & 2 & 4.9 & 0 \\
\hline 2009 & 3.2 & 0 & 0.5 & 2.8 & 5 & 5.6 & 5.9 & 6.1 & 3.5 & 2.6 & 1.1 & 3.7 & 5.1 & 2.8 & 3.9 & 2.4 & 2 \\
\hline 2010 & 3.6 & 0 & 0 & 1.9 & 3.9 & 7 & 5.3 & 6.6 & 1.4 & 3.4 & 9.7 & 4.8 & 1.3 & 8.3 & 1.9 & 2.4 & 5.8 \\
\hline 2011 & 3.6 & 1.7 & 0.5 & 0.5 & 5.3 & 8.4 & 4.7 & 3.2 & 4.1 & 4.2 & 2.1 & 4.7 & 0 & 6.8 & 3.8 & 9.3 & 7.7 \\
\hline 2012 & 2.7 & 0 & 1.9 & 1.8 & 3.8 & 4.4 & 3.1 & 2.1 & 4 & 3.3 & 2.1 & 0 & 2.4 & 8.1 & 3.7 & 0 & 5.7 \\
\hline 2013 & 3.4 & 0.4 & 0 & 1.2 & 5 & 6.8 & 4 & 5.1 & 4.8 & 4.4 & 2.8 & 4.2 & 3.4 & 0 & 7.1 & 4.3 & 7.1 \\
\hline 2014 & 3.9 & 0.4 & 0.3 & 1.7 & 5.9 & 3 & 5 & 6.2 & 1.1 & 4.7 & 3.4 & 3.9 & 7.3 & 4.7 & 11.7 & 10.2 & 15.2 \\
\hline 2015 & 3.3 & 0 & 1.5 & 2.3 & 3.9 & 7.6 & 8.2 & 6 & 2.6 & 2 & 2.5 & 1.9 & 6.1 & 2.3 & 1.6 & 0 & 3.3 \\
\hline 2016 & 3.5 & 0 & 0 & 1.3 & 4.4 & 5.3 & 6.7 & 5.7 & 2.6 & 3.3 & 3.4 & 2.9 & 6.2 & 9.4 & 3.3 & 4 & 6.7 \\
\hline APC & 1.6 & - & - & -4.8 & 3.1 & 0.2 & 3.6 & 2.4 & - & 5.1 & 3.5 & - & - & - & 1.3 & - & - \\
\hline $\begin{array}{l}\text { P- } \\
\text { value }\end{array}$ & 0.2 & - & - & 0.3 & 0.2 & 0.9 & 0.2 & 0.5 & - & 0.2 & 0.6 & - & - & - & 0.8 & - & - \\
\hline $\mathrm{Cl}$ & {$[-0.8,4.2]$} & & - & $\begin{array}{l}\text { [-14.1, } \\
5.5]\end{array}$ & $\begin{array}{l}{[-2.1,} \\
8.5]\end{array}$ & $\begin{array}{l}{[-5.3,} \\
6.0]\end{array}$ & $\begin{array}{l}{[-2.6,} \\
10.2]\end{array}$ & $\begin{array}{l}{[-5.3,} \\
10.8]\end{array}$ & & $\begin{array}{l}{[-2.6,} \\
13.5]\end{array}$ & $\begin{array}{l}{[-9.3} \\
18.2]\end{array}$ & & & - & $\begin{array}{l}{[-9.4,} \\
13.4]\end{array}$ & & - \\
\hline
\end{tabular}

TABLE 3: Trend analysis for non-Hodgkin lymphoma ASR per 100,000 in males by age group per year in Lebanon from 2005 to 2016

ASR, age-specific rate; APC, annual percent change 


\begin{tabular}{|c|c|c|c|c|c|c|c|c|c|c|c|c|c|c|c|c|c|}
\hline \multirow{2}{*}{ Year } & \multirow{2}{*}{$\begin{array}{l}\text { Average } \\
\text { ASR }\end{array}$} & \multicolumn{16}{|c|}{ ASR } \\
\hline & & $\begin{array}{l}0- \\
4 y\end{array}$ & $\begin{array}{l}5- \\
9 y\end{array}$ & $\begin{array}{l}10- \\
14 y\end{array}$ & $15-19 y$ & $\begin{array}{l}20- \\
24 y\end{array}$ & $25-29 y$ & $30-34 y$ & $35-39 y$ & $40-44 y$ & $45-49 y$ & $50-54 y$ & $55-59 y$ & $60-64 y$ & $65-69 y$ & $70-74 y$ & $75+y$ \\
\hline 2005 & 11.3 & 0 & 1.2 & 1 & 1.6 & 2.1 & 6.1 & 2.7 & 9.4 & 14.1 & 14.7 & 22.6 & 26.2 & 31.8 & 43.1 & 81.4 & 72.5 \\
\hline 2006 & 11.9 & 1.3 & 2.3 & 2.4 & 3.6 & 0 & 7.2 & 3.3 & 4.6 & 11.3 & 13.6 & 25.6 & 37.4 & 29.9 & 45.7 & 64.6 & 85.7 \\
\hline 2007 & 10.2 & 0 & 1.8 & 0 & 2.2 & 2.1 & 4.8 & 6.6 & 6.8 & 12.2 & 13.5 & 27.3 & 32.8 & 27.8 & 35.7 & 52.7 & 51.1 \\
\hline 2008 & 11.6 & 0 & 1 & 0.5 & 1.5 & 4.2 & 8.8 & 5.7 & 5.7 & 9.6 & 14.5 & 21.1 & 22.1 & 35.9 & 50 & 63.5 & 103 \\
\hline 2009 & 12 & 0.6 & 1 & 1.9 & 2.5 & 4.1 & 2.7 & 6.7 & 11.9 & 6.9 & 19.7 & 30.6 & 24.3 & 28.3 & 45.2 & 76.8 & 81.4 \\
\hline 2010 & 12.4 & 0.6 & 1.9 & 0.9 & 2.4 & 4.5 & 5.3 & 4.9 & 9 & 14.4 & 24.7 & 16.8 & 27.6 & 36.1 & 38.6 & 58.9 & 107.2 \\
\hline 2011 & 12.8 & 0.6 & 1.9 & 1.8 & 1.9 & 4.9 & 5.7 & 9.1 & 6.8 & 13.3 & 20.1 & 31.9 & 38.3 & 34.1 & 36.1 & 53.3 & 86.3 \\
\hline 2012 & 13.7 & 1.1 & 0.5 & 0.9 & 1.9 & 3.4 & 10.7 & 8.5 & 2.7 & 9.8 & 31.2 & 30.2 & 41.3 & 36.2 & 52.3 & 43.3 & 96.1 \\
\hline 2013 & 10.8 & 0.9 & 1.2 & 1.5 & 3.3 & 3 & 3.5 & 4.2 & 8.3 & 6.6 & 14 & 22.3 & 33.7 & 21.4 & 42.3 & 53.8 & 96.1 \\
\hline 2014 & 14.3 & 0.7 & 0.6 & 0.3 & 2.9 & 3 & 3.1 & 6.2 & 11.7 & 8 & 27.7 & 30.8 & 41.6 & 41.3 & 65.3 & 47 & 120 \\
\hline 2015 & 12.5 & 0 & 0.9 & 1 & 1.1 & 3.2 & 3.7 & 5.2 & 4.7 & 9.8 & 27.1 & 23.7 & 27.6 & 41.7 & 65.7 & 54.1 & 94.5 \\
\hline 2016 & 11 & 1.1 & 0 & 1 & 1.8 & 1.9 & 3.5 & 4.1 & 6.3 & 6.6 & 22.8 & 28.9 & 26 & 43.5 & 46.4 & 42.5 & 63.6 \\
\hline APC & 0.9 & - & - & - & -1.6 & - & -5.3 & 2.9 & -1.1 & $-4.6^{*}$ & $6.1^{*}$ & 1.3 & 1.0 & 2.6 & 2.8 & $-4.2^{\star}$ & 1.9 \\
\hline $\begin{array}{l}\text { P- } \\
\text { value }\end{array}$ & 0.3 & - & - & - & 0.6 & - & 0.1 & 0.4 & 0.8 & $<0.05$ & $<0.05$ & 0.4 & 0.6 & 0.1 & 0.1 & $<0.05$ & 0.4 \\
\hline $\mathrm{Cl}$ & {$[-0.9,2.7]$} & - & - & - & $\begin{array}{l}{[-7.9,} \\
5.2]\end{array}$ & - & $\begin{array}{l}{[-12.1,} \\
2.1]\end{array}$ & $\begin{array}{l}{[-3.9,} \\
10.1]\end{array}$ & $\begin{array}{l}{[-9.0} \\
7.4]\end{array}$ & $\begin{array}{l}{[-8.9,-} \\
0.1]\end{array}$ & $\begin{array}{l}{[1.5,} \\
11.0]\end{array}$ & $\begin{array}{l}{[-2.4} \\
5.1]\end{array}$ & $\begin{array}{l}\text { [-3.1, } \\
5.3]\end{array}$ & $\begin{array}{l}{[-1.0,} \\
6.3]\end{array}$ & $\begin{array}{l}{[-0.6,} \\
6.3]\end{array}$ & $\begin{array}{l}{[-6.7,-} \\
1.6]\end{array}$ & $\begin{array}{l}{[-2.5,} \\
6.5]\end{array}$ \\
\hline
\end{tabular}

\section{TABLE 4: Trend analysis for non-Hodgkin lymphoma ASR per 100,000 in females by age group per year in Lebanon from 2005 to 2016}

ASR, age-specific rate; APC, annual percent change

*APC significantly different than zero.

HL demonstrated a bimodal distribution with two peaks, the first being between the ages of 20 and 40 and the second being in people older than 60 , while $76 \%$ of NHL patients were 40 years or older. The group that had the most number of cases in both cancer types consisted of males older than 75 years with an average incidence of 8.31 HL cases per 100,000 and 92.8 NHL cases per 100,000. The group with the lowest incidence in both malignancies was the one aged 0-4 years with average rates of $0.2 \mathrm{HL}$ cases per 100,000 in males and 0.57 NHL cases in females.

Throughout our study, there was no significant change in HL incidence rates in both males $(\mathrm{P}=0.2, \mathrm{CI}[-1.1$, 5.1]) and females $(\mathrm{P}=0.2$, $\mathrm{CI}[-0.8,4.2])$ as seen in Figures 1,2 . However, a significant increase was noted in NHL rates in males from 2005 to 2014 (P<0.05, CI [1.4, 3.9]) (Figures 2, 3). As for age-specific incidence rates, studying both genders revealed a significant decrease in HL cases in males aged 10 to 14 ( $\mathrm{P}<0.05$, CI $[-14.6,-5.5])$ (Tables 1,2$)$. In females, age-specific trends of NHL showed a significant decrease in rates for age groups $40-44$ years $(\mathrm{P}<0.05$, CI $[-8.9,-0.1])$ and $70-74$ years $(\mathrm{P}<0.05$, CI $[-6.7,-1.6])$ and a significant increase for age group 45-49 years $(\mathrm{P}<0.05$, CI $[1.5,11.0])$ throughout the 12 years (Tables 3,4$)$. 


\section{Cureus}

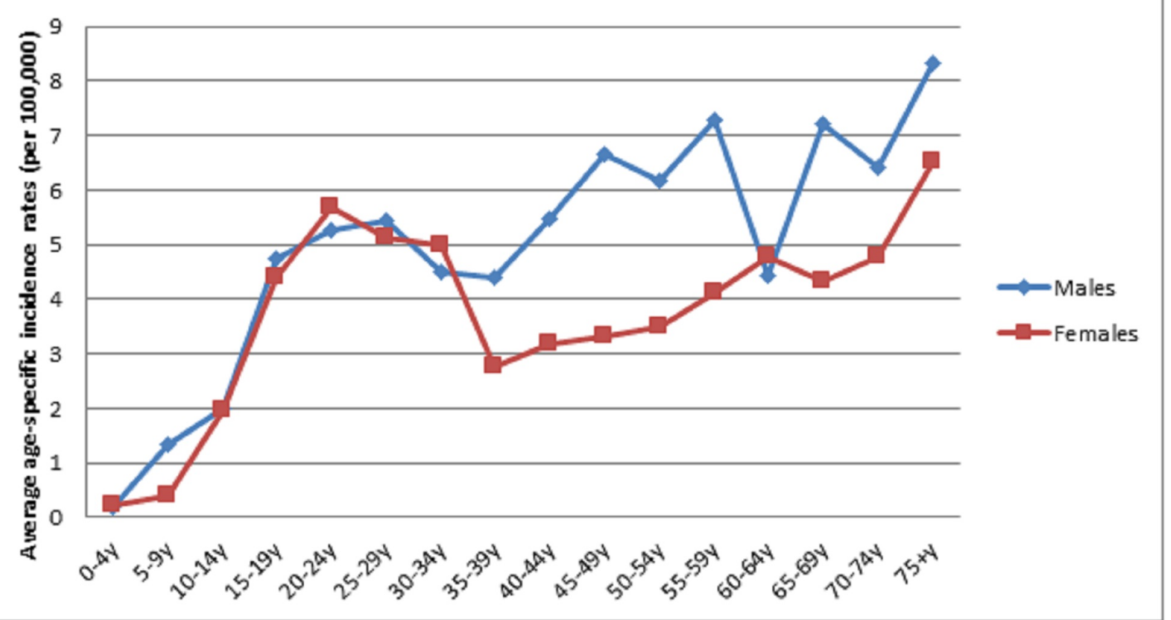

(a)

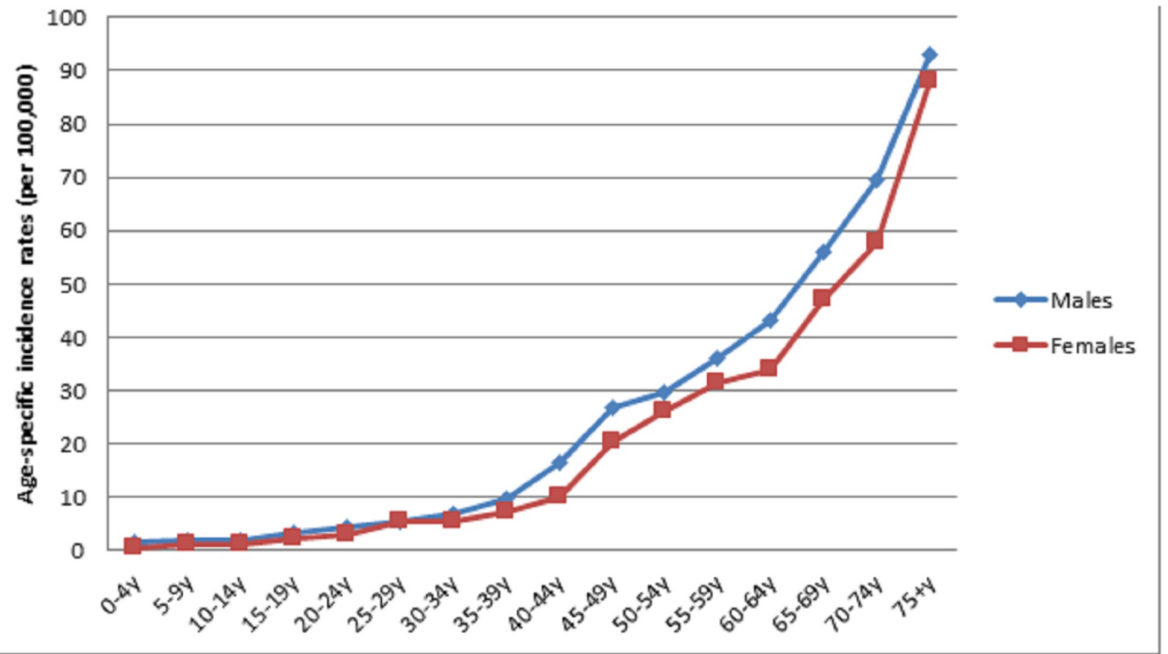

(b)

FIGURE 1: Gender and average age-specific incidence rates (per 100,000 population) for (a) Hodgkin and (b) non-Hodgkin lymphoma in Lebanon from 2005 to 2016 


\section{Cureus}

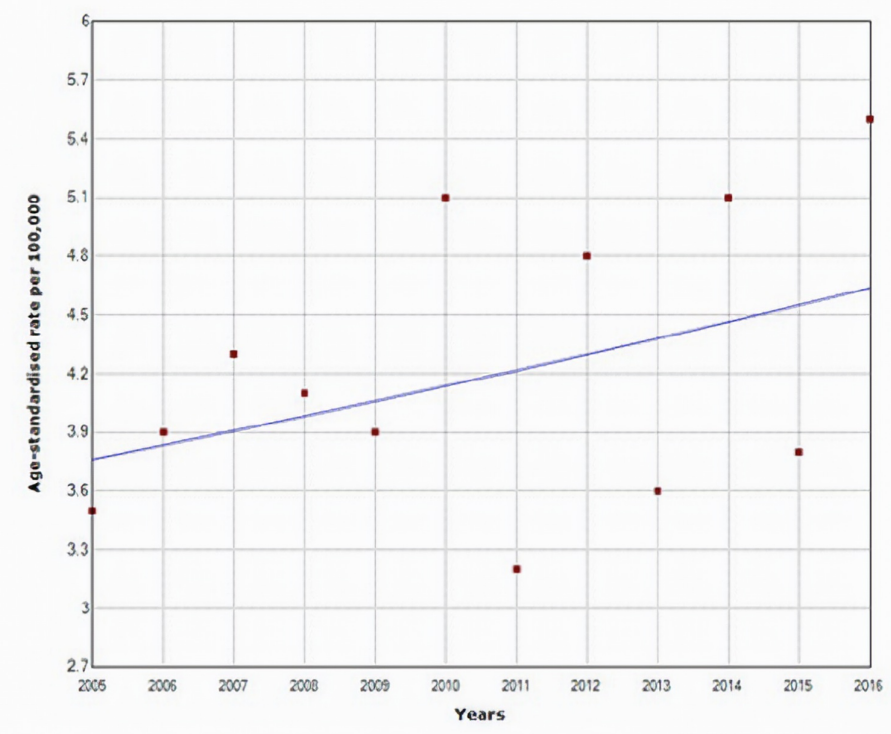

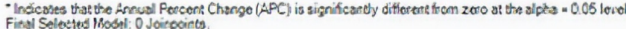

(a)

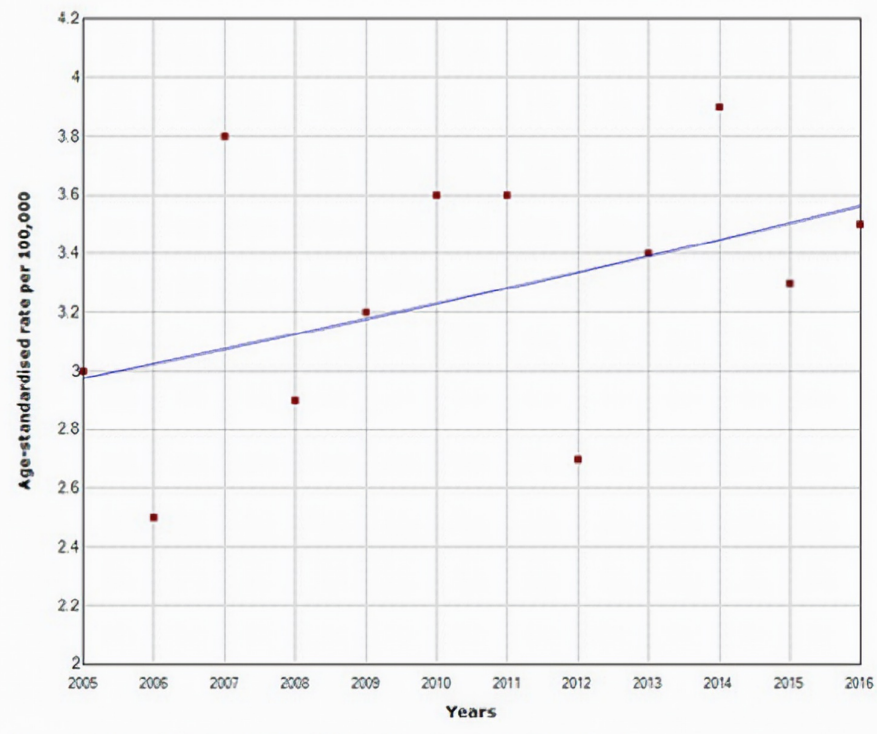

- Otraerved $20050-20160 \mathrm{APC}=1.84$

(b)

FIGURE 2: Trends of age-specific rates for Hodgkin lymphoma among (a) males and (b) females in Lebanon from 2005 to 2016 


\section{Cureus}

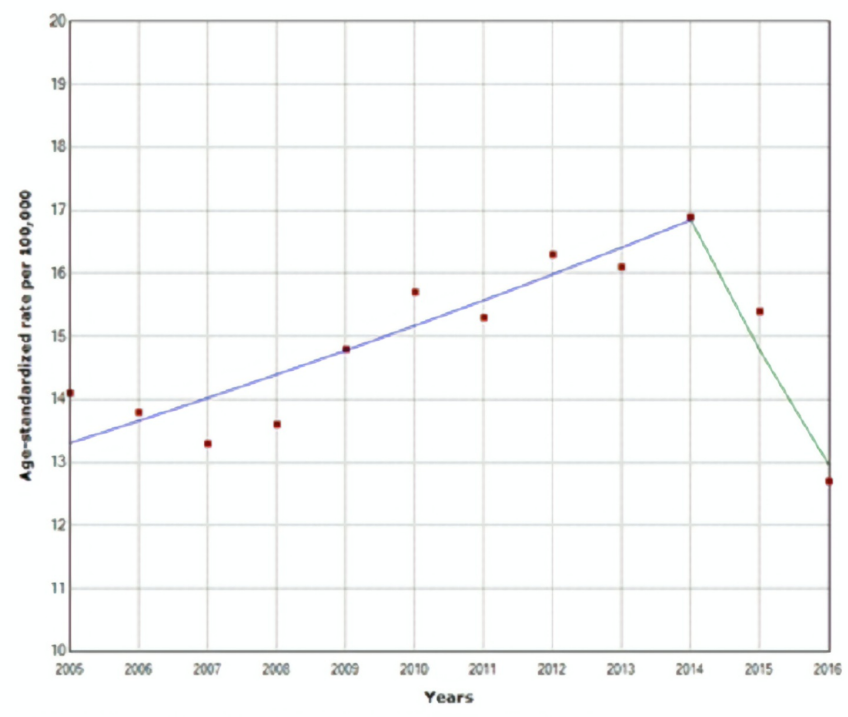

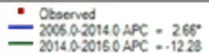

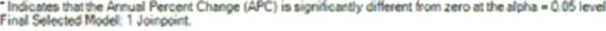

(a)

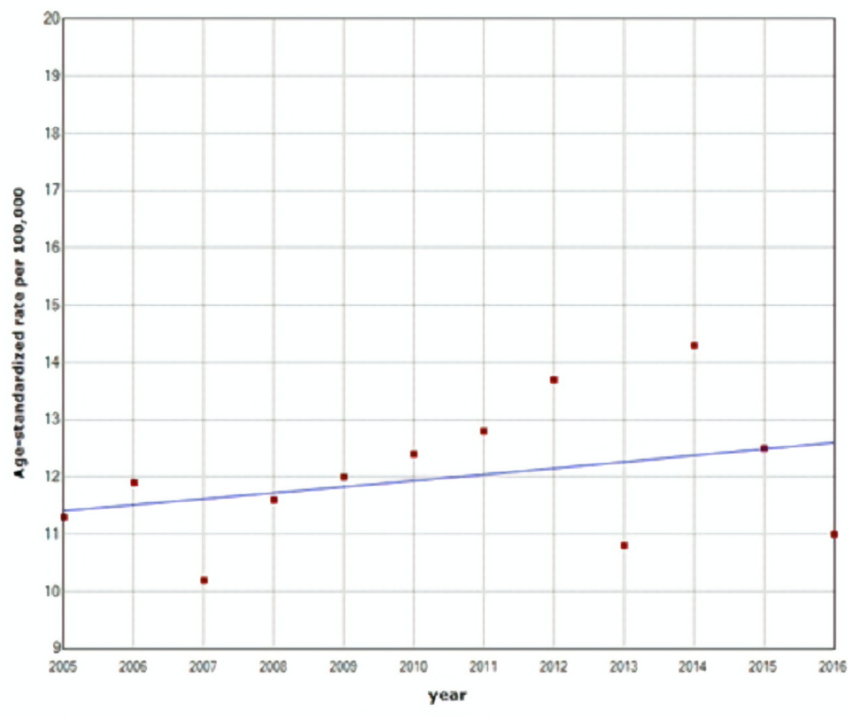

- Observed $20060.20160 \mathrm{APC} \cdot 0.91$

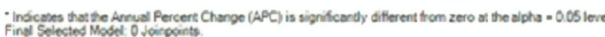

(b)

FIGURE 3: Trends of age-specific rates for non-Hodgkin lymphoma among (a) males and (b) females in Lebanon from 2005 to 2016

Relying on our 10-year predictions, NHL incidence rates are expected to significantly rise from 2016 to 2026 with an APC of 1.85 in males and 1.49 in females ( $<$ < 0.05, CI 95\%) (Table 5). Moreover, no significant variation is expected in HL rates for both males and females till 2026 (Table 6). 


\section{Cureus}

\begin{tabular}{|l|l|l|l|l|l|l|l|}
\hline Sex & 2016 (year) & 2021 (year) & APC & Trend & 2026 (year) & APC & Trend \\
\hline Male & 12.7 & 16.4 & 3.98 & Rising & 17.1 & $1.85^{\star}$ & Rising $^{\star}$ \\
\hline Female & 11 & 13.1 & 2.76 & Rising & 13.7 & $1.49^{\star}$ & Rising $^{\star}$ \\
\hline
\end{tabular}

TABLE 5: Ten-year prediction of incidence per 100,000 of non-Hodgkin lymphoma in both males and females and their APC

APC, annual percent change

*Significantly different than zero.

\begin{tabular}{|c|c|c|c|c|c|c|c|}
\hline Sex & 2016 (year) & 2021 (year) & APC & Trend & 2026 (year) & APC & Trend \\
\hline Male & 5.5 & 4.3 & -1.46 & Declining & 6.1 & 1.39 & Rising \\
\hline Female & 3.5 & 3.3 & 0.04 & Stable & 3.8 & 1.19 & Rising \\
\hline
\end{tabular}

TABLE 6: Ten-year prediction of incidence per 100,000 of Hodgkin lymphoma in both males and females and their APC

APC, annual percent change

\section{Discussion}

Of the 9,048 new cases of lymphoma reported in Lebanon from 2005 to 2016, HL accounted for $24 \%$ and NHL for $76 \%$. These results are consistent with the epidemiological profiling of these malignancies done previously in Lebanon [12]. NHL was the seventh most common malignancy during the time period studied, which is also consistent with previous reports from the country [10].

Similar to previous research, lymphoid malignancies affected males significantly more than females in our study $[13,14]$. However, female predominance might be noted in some subtypes of NHL, like marginal zone and follicular lymphoma [15]. NHL was significantly more prevalent in both genders [14]. Sex predilection in lymphomas may stem from the fact that environmental exposures and working conditions that are often linked to uncontrolled lymphoproliferation tend to occur in male-driven careers such as industrial or engineering work [15]. Given that such patterns of male predominant careers are also prevalent in Lebanon, it comes as no surprise that our results mirror these previous findings. Also, it has been suggested that gravidity plays an important protective role against NHL, explaining why males were more affected by this disease [14].

Previous reports from Lebanon have shown that the age distribution of HL in both genders was found to be bimodal [12]. Lebanon witnessed improvement in the efficiency of its healthcare system from 2000 to 2015 according to a study done by Ibrahim and Daneshvar [16]. This suggests that HL's bimodal distribution in Lebanon can be explained by the advancement of medical diagnostic studies. The implementation of highly sensitive techniques helps differentiate the various types of lymphomas and aids in diagnosing HL earlier [17]. NHL is usually more common in people older than 40 years, with the highest incidence found in people older than 70 years [18]. Therefore, the increase in life expectancy among the Lebanese population from a median age of 60.5 years in 1950 to 78.8 years in 2015 must have markedly impacted the total number of NHL cases in our study [19].

Lebanon has been witnessing an accelerating rate of obesity, increasing from $54.4 \%$ to $65.0 \%$ over the past decade, as provided by national surveys conducted by the MoPH and WHO [20]. An increase in the body mass index in most Lebanese age groups has been also described by different studies in the past decade [21]. Accordingly, this escalating rate of obesity might explain the increasing incidence of HL cases in Lebanon, given that a causative relationship has been already established between obesity and this lymphoma subtype [22].

HIV has been emerging tremendously in the MENA region during the past two decades. As reported by the Joint United Nations Programme on HIV/AIDS (UNAIDS), new HIV infections increased by 31\% from 2001 to 2013, representing the highest rate among all regions in the world [23]. Some studies in Lebanon have also 
demonstrated a rise in the prevalence rate of HIV infections locally, in the past few years [24]. Because HIV has been highly associated with a higher risk of both HL and NHL when compared to previously healthy individuals, this increasing trend in HIV infections among the Lebanese population can help explain the increase in amounts of cases of both cancers in the country over the studied period [25].

Concerning other infectious and communicable diseases, Epstein-Barr virus (EBV) infection is a well-known risk factor for both NHL and HL [26]. Despite its wide prevalence especially in developing countries, no data is available in Lebanon. Helicobacter pylori, another common pathogen in developing countries, is a known risk factor for gastric mucosa-associated lymphoid tissue (MALT) lymphoma, a subtype of NHL [27]. EBV and H. pylori remain two well-known risk factors for lymphoma, but no sufficient local data is present to correlate them with the increasing prevalence of lymphomas in Lebanon. Therefore, more research must be published on these two pathogens to help better understand their associated diseases such as HL and NHL.

First-degree relatives of patients with lymphoma have a significantly elevated risk of developing the same malignancy, more commonly of the same subtype [28]. In addition, these correlations do not seem to be confounded by other risk factors, all of which raises the suspicion of genetic risk factors and familial predisposition to lymphomas. Furthermore, genome-wide association studies have successfully identified multiple single nucleotide polymorphisms from 41 loci predominately associated with specific subtypes [29]. More specifically, genes associated with risk for HL were most commonly located at different major histocompatibility complex (MHC)/human leukocyte antigen (HLA) loci. However, these genetic associations that are believed to increase the risk of HL are more likely multiple common risk alleles, rather than a single isolated gene [30]. In Lebanon, no studies have been conducted to complement the present knowledge of genetic risk factors for HL and NHL.

Both HL and NHL are projected to increase by 2026. This can be explained by looking back at the risk factors involved in pathogenesis of both diseases. Preventable risk factors such as environmental exposure to carcinogens are not set to decrease, and with the increase in toxic waste present in the country, one can only expect that exposure to said compounds will increase. Obesity and infections are also set to follow the other worldwide trends in increasing. These factors can help explain why the HL and NHL will continue to increase in Lebanon in the following 10 years.

To the best of our knowledge, this is the first study exploring the trends, characteristics, and projections of HL and NHL in Lebanon. Nevertheless, a few limitations are present. First, as our data was extracted from the NCR provided by the MoPH, the validity of our results depends on the reliability of the source. Second, considering that the NCR does not provide data on mortality rates or cancer staging, we were only able to identify the incidence rates of lymphoid neoplasms and evaluate their changes throughout the years.

\section{Conclusions}

An increase in lymphoma incidence rates has been noted in Lebanon during 2005-2016. This increase can be attributed to an aging population and early cancer detection, along with other preventable risk factors. A deeper understanding of lymphoma incidence in Lebanon is largely dependent on further studies targeting the genesis of different subtypes and various modifiable and unmodifiable risk factors prevalent in the society. Ten-year projections plotted by this study denote a further increase in lymphoma cases. In front of these alarming findings, the MoPH and concerned non-governmental organizations should promote campaigns to increase society's knowledge of different risk factors associated with lymphoid malignancies and implement measures to decrease their prevalence.

\section{Additional Information}

\section{Disclosures}

Human subjects: All authors have confirmed that this study did not involve human participants or tissue. Animal subjects: All authors have confirmed that this study did not involve animal subjects or tissue. Conflicts of interest: In compliance with the ICMJE uniform disclosure form, all authors declare the following: Payment/services info: All authors have declared that no financial support was received from any organization for the submitted work. Financial relationships: All authors have declared that they have no financial relationships at present or within the previous three years with any organizations that might have an interest in the submitted work. Other relationships: All authors have declared that there are no other relationships or activities that could appear to have influenced the submitted work.

\section{Acknowledgements}

The authors would like to acknowledge that both A.A.S. and M.J. contributed equally to this work.

\section{References}

1. Fares MY, Salhab HA, Khachfe HH, Khachfe HM: Breast cancer epidemiology among Lebanese women: an 11-year analysis. Medicina. 2019, 55:463. 10.3390/medicina55080463

2. Bray F, Ferlay J, Soerjomataram I, Siegel RL, Torre LA, Jemal A: Global cancer statistics 2018: GLOBOCAN 
estimates of incidence and mortality worldwide for 36 cancers in 185 countries. CA Cancer J Clin. 2018, 68:394-424. 10.3322/caac.21492

3. Storck K, Brandstetter M, Keller U, Knopf A: Clinical presentation and characteristics of lymphoma in the head and neck region. Head Face Med. 2019, 15:1. 10.1186/s13005-018-0186-0

4. Swerdlow SH, Campo E, Pileri SA, et al.: The 2016 revision of the World Health Organization classification of lymphoid neoplasms. Blood. 2016, 127:2375-2390. 10.1182/blood-2016-01-643569

5. Huh J: Epidemiologic overview of malignant lymphoma. Korean J Hematol. 2012, 47:92-104. 10.5045/kjh.2012.47.2.92

6. Cerhan JR, Kricker A, Paltiel O, et al.: Medical history, lifestyle, family history, and occupational risk factors for diffuse large B-cell lymphoma: the InterLymph Non-Hodgkin Lymphoma Subtypes Project. J Natl Cancer Inst Monogr. 2014, 2014:15-25. 10.1093/jncimonographs/lgu010

7. Hartge P, Smith MT: Environmental and behavioral factors and the risk of non-Hodgkin lymphoma . Cancer Epidemiol Biomarkers Prev. 2007, 16:367-368. 10.1158/1055-9965.EPI-07-0031

8. Khachfe HH, Salhab HA, Fares MY, Khachfe HM: Probing the colorectal cancer incidence in Lebanon: an 11year epidemiological study [online ahead of print]. J Gastrointest Cancer. 2019, 10.1007/s12029-019-00284-Z

9. National Cancer Registry (NCR) of Lebanon. (2020). Accessed: April 2020: https://www.moph.gov.lb/en/Pages/national-cancer-registry.

10. Khachfe HH, Rahal Z, Sammouri J, et al.: Cancer in Lebanon: a review of incidence rates from 2008 to 2015 and projections till 2025. South Asian J Cancer. 2019, 60:61. 10.4103/sajc.sajc_301_19

11. Cancer Trends Progress Report - 2009/2010 Update . (2010). Accessed: April 2020: https://progressreport.cancer.gov/sites/default/files/archive/report2009.pdf.

12. Sader-Ghorra C, Rassy M, Naderi S, Kourie HR, Kattan J: Type distribution of lymphomas in Lebanon: fiveyear single institution experience. Asian Pac J Cancer Prev. 2014, 15:5825-5828. 10.7314/apjcp.2014.15.14.5825

13. SEER Cancer Statistics Review (CSR) 1975-2017 . (2019). Accessed: April 2020: https://seer.cancer.gov/csr/1975_2017/.

14. Horesh N, Horowitz NA: Does gender matter in non-Hodgkin lymphoma? Differences in epidemiology, clinical behavior, and therapy. Rambam Maimonides Med J. 2014, 5:e0038. 10.5041/rmmj.10172

15. Teras LR, DeSantis CE, Cerhan JR, Morton LM, Jemal A, Flowers CR: US lymphoid malignancy statistics by World Health Organization subtypes. CA Cancer J Clin. 2016, 66:443-459. 10.3322/caac.21357

16. Ibrahim MD, Daneshvar S: Efficiency analysis of healthcare system in Lebanon using modified data envelopment analysis. J Healthc Eng. 2018, 2018:2060138. 10.1155/2018/2060138

17. Medeiros LJ, Greiner TC: Hodgkin's disease. Cancer. 1995, 75:357-369. 10.1002/1097-0142(19950101)75:1+ $<357:$ :AID-CNCR2820751318>3.0.CO;2-A

18. National Guideline Alliance (UK): 1, Epidemiology. In Non-Hodgkin's Lymphoma: Diagnosis and Management. National Institute for Health and Care Excellence, London; 2016. 52:21-24.

19. World population prospects. (2019). Accessed: May 2020: https://population.un.org/wpp/.

20. Nasreddine L, Naja F, Chamieh MC, Adra N, Sibai AM, Hwalla N: Trends in overweight and obesity in Lebanon: evidence from two national cross-sectional surveys (1997 and 2009). BMC Public Health. 2012, 12:798. 10.1186/1471-2458-12-798

21. Chamieh MC, Moore HJ, Summerbell C, Tamim H, Sibai AM, Hwalla N: Diet, physical activity and socioeconomic disparities of obesity in Lebanese adults: findings from a national study. BMC Public Health. 2015, 15:279. 10.1186/s12889-015-1605-9

22. Larsson SC, Wolk A: Body mass index and risk of non-Hodgkin's and Hodgkin's lymphoma: a meta-analysis of prospective studies. Eur J Cancer. 2011, 47:2422-2430. 10.1016/j.ejca.2011.06.029

23. UNAIDS: the Gap Report. (2014). Accessed: May 2020: https://www.unaids.org/sites/default/files/media_asset/UNAIDS_Gap_report_en.pdf.

24. Assi A, Abu Zaki S, Ghosn J, et al.: Prevalence of HIV and other sexually transmitted infections and their association with sexual practices and substance use among 2238 MSM in Lebanon. Sci Rep. 2019, 9:15142. 10.1038/s41598-019-51688-7

25. Dal Maso L, Franceschi S, Polesel J, et al.: Risk of cancer in persons with AIDS in Italy, 1985-1998 . Br J Cancer. 2003, 89:94-100. 10.1038/sj.bjc.6601017

26. Hjalgrim H, Askling J, Rostgaard K, et al.: Characteristics of Hodgkin's lymphoma after infectious mononucleosis. N Engl J Med. 2003, 349:1324-1332. 10.1056/NEJMoa023141

27. Parsonnet J, Hansen S, Rodriguez L, et al.: Helicobacter pylori infection and gastric lymphoma . N Engl J Med. 1994, 330:1267-1271. 10.1056/nejm199405053301803

28. Goldin LR, Björkholm M, Kristinsson SY, Turesson I, Landgren O: Highly increased familial risks for specific lymphoma subtypes. Br J Haematol. 2009, 146:91-94. 10.1111/j.1365-2141.2009.07721.x

29. Cerhan JR, Slager SL: Familial predisposition and genetic risk factors for lymphoma . Blood. 2015, 126:22652273. 10.1182/blood-2015-04-537498

30. Sud A, Hemminki K, Houlston RS: Candidate gene association studies and risk of Hodgkin lymphoma: a systematic review and meta-analysis. Hematol Oncol. 2017, 35:34-50. 10.1002/hon.2235 